\title{
Prohibit, Protect, or Adapt? The Changing Role of Volunteers in Palliative and Hospice Care Services During the COVID-19 Pandemic. A Multinational Survey (Covpall)
}

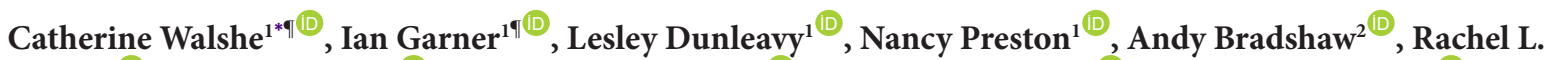

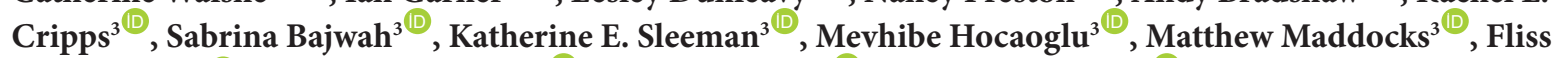

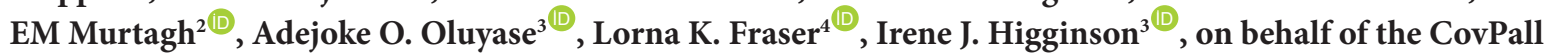 \\ Study Team ${ }^{\#}$
}

\begin{abstract}
Background: Volunteers are common within palliative care services, and provide support that enhances care quality. The support they provided, and any role changes, during the coronavirus disease 2019 (COVID-19) pandemic are unknown. The aim of this study is to understand volunteer deployment and activities within palliative care services, and to identify what may affect any changes in volunteer service provision, during the COVID-19 pandemic.

Methods: Multi-national online survey disseminated via key stakeholders to specialist palliative care services, completed by lead clinicians. Data collected on volunteer roles, deployment, and changes in volunteer engagement. Analysis included descriptive statistics, a multivariable logistic regression, and analysis of free-text comments using a content analysis approach.

Results: 458 respondents: 277 UK, 85 rest of Europe, and 95 rest of the world. $68.5 \%$ indicated volunteer use preCOVID-19 across a number of roles (from 458): direct patient facing support (58.7\%), indirect support (52.0\%), back office $(48.5 \%)$ and fundraising (45.6\%). $11 \%$ had volunteers with COVID-19. Of those responding to a question on change in volunteer deployment ( 328 of 458$)$ most $(256 / 328,78 \%)$ indicated less or much less use of volunteers. Less use of volunteers was associated with being an in-patient hospice, (odds ratio $[\mathrm{OR}]=0.15,95 \% \mathrm{CI}=0.07-0.3, P<.001$ ). This reduction in volunteers was felt to protect potentially vulnerable volunteers, with policy changes preventing volunteer support. However, adapting was also seen where new roles were created, or existing roles pivoted to provide virtual support.

Conclusion: Volunteers were mostly prevented from supporting many forms of palliative care which may have quality and safety implications given their previously central roles. Volunteer re-deployment plans are needed that take a more considered approach, using volunteers more flexibly to enhance care while ensuring safe working practices. Consideration needs to be given to widening the volunteer base away from those who may be considered to be most vulnerable to COVID-19.

Keywords: Palliative Care, COVID-19, Volunteers

Copyright: @ 2022 The Author(s); Published by Kerman University of Medical Sciences. This is an open-access article distributed under the terms of the Creative Commons Attribution License (https://creativecommons.org/licenses/ by/4.0), which permits unrestricted use, distribution, and reproduction in any medium, provided the original work is properly cited.

Citation: Walshe C, Garner I, Dunleavy L, et al. Prohibit, protect, or adapt? The changing role of volunteers in palliative and hospice care services during the COVID-19 pandemic. A multinational survey (Covpall). Int J Health Policy Manag. 2022;11(10):2146-2154. doi:10.34172/ijhpm.2021.128
\end{abstract}

Article History:

Received: 12 April 2021

Accepted: 6 September 2021 ePublished: 8 September 2021

\footnotetext{
${ }^{\#}$ Membership of the CovPall Study Team is provided in the Acknowledgments.

"Both authors contributed equally to this paper.

\section{*Correspondence to:} Catherine Walshe Email: c.walshe@lancaster.ac.uk
}

\section{Background}

Specialist palliative and hospice care services have proven to be critically important as part of the whole-system management of the coronavirus disease 2019 (COVID-19) pandemic. ${ }^{1-3}$ They are closely involved in the symptom management of those who are dying or who have challenging symptoms (both dying with COVID-19 and from COVID-19) and, at times, services have provided additional bed capacity to help manage the surge in patient numbers in the wider healthcare system. Whilst paid staff are central to the provision of palliative and hospice care services, volunteers are also major contributors to the way that high quality, safe services are provided across the world. ${ }^{4}$ In some services volunteers can be more numerous than paid staff, with one UK survey identifying 1.5 volunteers to every paid member of staff, ${ }^{5}$ providing a great number of hours of care and support, typically up to 8 hours a week. ${ }^{6}$ It is estimated that each UK volunteer provides at least $£ 1500$ of value per annum to the organisation. ${ }^{7}$ Volunteers also offer stability; a Belgian survey identified that most volunteers had been in their current care organisation for at least 6 years (57\%), and $36 \%$ for over 10 years. ${ }^{6}$

Volunteers can support many different aspects of palliative 


\section{Key Messages}

Implications for policy makers

- Policy-makers should take account of the skills and contributions of volunteers to healthcare services when planning how to respond to emergencies, including epidemic and pandemic situations.

- Volunteers can remain an integral part of an organisation's pandemic response.

- Policies should plan to take account both of potential vulnerabilities of volunteer populations, but also reflect on the flexibility and potential responsiveness of volunteers.

Implications for the public

Volunteers are typically integral to the way that palliative care services are usually delivered. However, during the coronavirus disease 2019 (COVID-19) pandemic most organisations stopped using volunteers almost immediately, or curtailed their activities. This has potential implications for staff workload, and the responsiveness, quality and safety of care. Organisations should work with volunteers and those who are interested in volunteering for organisations to develop policies and procedures that enable safe and flexible deployment of volunteers in such emergency situations. It is likely that expanding the typical age range of volunteers to include those who are younger, and exploring virtual or remote forms of volunteering may also enable continued use of volunteers in the future.

and hospice care across all settings, including in-patient palliative care units, hospital and home palliative care teams, home nursing services and in the community. ${ }^{8,9}$ Whilst volunteers traditionally contributed mostly to 'back office' functions such as finance or catering, as well as running shops and other fundraising activities, they are increasingly found in patient facing roles. ${ }^{10-13}$ When providing patientfacing care, typically the focus is on psychosocial support, including spiritual care, signposting to services, as well as care tasks. ${ }^{5,6,10,14-16}$ Volunteers complement professional care by being a unique face of care for patients, occupying a liminal space between professionals, family and patients. ${ }^{8,17,18}$

Care from volunteers has been found to be safe, effective, and appreciated by patients. ${ }^{9}$ Benefits to people who receive care are assumed to include improvements in quality of life and enhancement of wellbeing, ${ }^{9,10,11,18-21}$ and one study also indicated a survival advantage for those supported by volunteers. ${ }^{22}$ Volunteers themselves benefit from their volunteering activities reporting that it becomes a major part of their lives, ${ }^{4}$ changing their own perspectives and values. ${ }^{23-25}$

No data are yet available on the impact of the COVID-19 pandemic on volunteers and the role and service they provide to palliative and hospice services during this time. Effective use of volunteers is highlighted as a possible response to the pandemic, ${ }^{26}$ with calls for mobilising and training a citizen volunteer workforce that is ready and able to connect with patients in need of basic social support. ${ }^{27}$ It is important that the role of volunteers during the COVID-19 pandemic is understood, given the dependence many palliative care services have on them for quality care provision and to maintain a safe organisation.

\section{Methods}

Aim

To understand volunteer deployment and activities within palliative and hospice care services, and to identify what may affect any changes in volunteer service provision, during the COVID-19 pandemic.

Design

A cross-sectional design, with a single point of data collection using an online multi-national survey of hospice and specialist palliative care providers. This study is reported in accordance with the Strengthening the Reporting of Observational Studies in Epidemiology (STROBE) ${ }^{28}$ and the Checklist for Reporting Results of Internet E-Surveys (CHERRIES) ${ }^{29}$ reporting guidelines. This paper is part of the wider CovPall study ${ }^{1-3}$ that aims to understand the multi-national specialist palliative care response to COVID-19.

\section{Population and Setting}

Service leads were invited to take part in the online survey on behalf of their organisation if they provided a minimum of one of the following specialist palliative care services: inpatient palliative care, hospital palliative care, home palliative care and home nursing across any country.

\section{Sampling and Recruitment}

The survey was open to responses from 23/04/2020 to $31 / 07 / 2020$. An open invitation to participate was disseminated through advertisement and via palliative care and hospice organisations (Sue Ryder, Hospice UK, Scottish Partnership for Palliative Care, Marie Curie, European Association of Palliative Care, Together for Short Lives, and the palliativedrugs.com and https://pos-pal.org network). All interested eligible services were provided with a link to complete the survey online, together with a participant information sheet. There was no targeted sampling across provider type or country, and respondents were not incentivised or reimbursed for completion. Completion indicated consent.

\section{Data Collection}

REDCap (an online web application that allows for the building and managing of surveys and databases) was used to collect data online with closed and free text survey responses, designed to shed light on the context for closed responses. Sites were given the option to enter the data online directly, be emailed the survey to complete and then return electronically, or complete the survey via telephone or video conferencing with a member of the study team. As well as general and COVID-19 related service information (see Supplementary 
file 1 for full survey), specific questions were asked about their use of volunteers, and the impact of COVID-19 on volunteers (Table 1).

\section{Data Analysis}

In the quantitative analyses, the primary outcome was a dichotomised variable about volunteer deployment postpandemic (a lot more/slightly more/about the same vs slightly less/much less volunteer use), collapsed from the initial fivepoint scale for those services that answered this question due to the skewed clustering in the answers to this question, hereafter more or less (which includes a proportion who answered 'about the same') volunteer use. The relationship between these two categories of volunteer use during the pandemic and a number of potential explanatory variables (service funding model; type of service provided; whether adult/child service; number of confirmed or suspected COVID-19 cases; personal protective equipment (PPE) shortages; staff shortages; whether service changes were made; whether services perceived themselves to be busy; and geography (a post-hoc categorisation of UK/Europe/ Rest of World recognising the unequal dispersion of answers across countries) were explored using frequency counts (for dichotomous variables) or median/interquartile range (for continuous non normally distributed variables). Differences between more or less volunteer use for dichotomous variable were assessed using chi-square $\left(\chi^{2}\right)$ analysis, with MannWhitney $U t$ tests for non-dichotomous data. Sample size (n) is also provided for Mann-Whitney $\mathrm{U} t$ tests. For the multivariable logistic regression model, the dependent variable was change in frequency of volunteer use (with 'less volunteer use' as the reference category), with explanatory variables chosen according to significance $(P<.05)$. For each explanatory variable the reference category was the answer 'no' for dichotomous variables, and the lowest denominator for non-dichotomous variables (eg, 'much less busy' for staff busyness), and for the outcome the 'less volunteer use' was the reference group. Model fit was assessed using Bayesian information criteria. Analysis was conducted in SPSS version 26.

For the analysis of free-text comments, data were extracted for the relevant questions in Table 1. As is common with free text data from surveys comments tended to be brief, expanding on answers to closed questions..$^{30,31}$ After initial familiarisation, a coding framework was inductively developed and applied to the free text data (by CW, IG) using a conventional content analysis technique. ${ }^{32}$ Coding and theme development were driven by the content of the free-text comments, with themes identified initially within, and then compared across, the sets of answers to each included question.

\section{Results}

A total of 458 responses were received, of which 314 (68.5\%) indicated they used volunteers pre-pandemic in any role, and with 328 answering the question about deployment during the pandemic (see Table 2 for details).

Further analyses only include data from the 328 services who responded to the question about volunteer deployment during the pandemic (Table 3). When comparing the 130 participants who did not provide answers on volunteer deployment compared to those who did, participants who did not answer this question had significantly more PPE shortages $\left(\chi^{2}=6.65, P=.01\right)$, staff shortages $\left(\chi^{2}=4.63, P=.03\right)$, and changes to hospital palliative care advanced team settings in response to COVID-19 $\left(\chi^{2}=4.59, P=.03\right)$. No further significant differences were found.

The multivariable logistic regression (Table 4) shows that there was a significant association between providing inpatient hospice care and reporting less use of volunteers than usual during the pandemic. Services who care for adult patients only were significantly associated with more volunteer use. No other variables were significantly associated with change in volunteer use compared to pre-COVID-19.

Analysis of free-text data identified two overarching themes. First, that of protecting and prohibiting volunteers from contributing in the ways that they did pre-pandemic. Second,

Table 1. Specific Survey Questions on Volunteer Use Within the CovPall Survey

If you had volunteer roles available within your service, what were they? (tick all that apply)
- Direct patient/family facing support (eg, befriending, home visits, inpatient unit care, family support groups/visiting etc)

- Indirect patient/family facing support (eg, reception functions, refreshments, driving /transport etc)

- Back office functions (eg, finance support, maintenance, gardening etc)

- Fundraising functions (eg, shop volunteers, lottery etc)

- Others (a box will open below)

Yes/No

Have you had volunteers with suspected or confirmed COVID-19.

What impact has this (volunteers with suspected or confirmed

COVID-19) on your service?

\begin{abstract}
Have you changed how your volunteers engage and where? Please give details.
\end{abstract}

How would you say you are deploying volunteers compared to before COVID-19?
Yes/No

- A lot more

- Slightly more

- About the same

- Slightly less

- Much less

Abbreviation: COVID-19, coronavirus disease 2019. 
Table 2. Descriptive Data on Volunteer Use Pre and During the COVID-19 Pandemic

\begin{tabular}{|c|c|c|c|}
\hline & $\begin{array}{l}\text { All Responses } \\
\qquad \begin{array}{c}(n=458) \\
\text { No. }(\%)\end{array}\end{array}$ & $\begin{array}{c}\text { Indicated Any Past } \\
\text { Volunteer Use }(n=314) \\
\text { No. }(\%)\end{array}$ & $\begin{array}{l}\text { Answered Question About Current } \\
\text { Volunteer Deployment (the Same or } \\
\text { More/Less) }(n=328) \\
\text { No. (\%) }\end{array}$ \\
\hline \multicolumn{4}{|l|}{ Geography } \\
\hline UK & $277(60.5)$ & $187(59.6)$ & $195(59.5)$ \\
\hline Europe & $85(18.6)$ & $59(18.8)$ & 62 (18.9) \\
\hline Missing & $1(0.2)$ & $1(0.3)$ & $0(0)$ \\
\hline \multicolumn{4}{|c|}{ Pre-pandemic volunteer roles } \\
\hline Direct support & $269(58.7)$ & $269(85.6)$ & $246(75.0)$ \\
\hline Indirect support & $238(51.9)$ & $238(75.7)$ & $218(66.4)$ \\
\hline Back office & $222(48.4)$ & $222(70.7)$ & $205(62.5)$ \\
\hline Fundraising & $209(45.6)$ & $209(66.5)$ & $189(58.1)$ \\
\hline Others & $51(11.1)$ & $51(16.2)$ & 49 (14.9) \\
\hline Missing & $0(0)$ & $0(0)$ & $0(0)$ \\
\hline \multicolumn{4}{|c|}{ Volunteers with COVID-19 } \\
\hline Yes & $38(8.3)$ & $36(11.4)$ & 36 (10.9) \\
\hline No & $369(80.6)$ & $260(82.8)$ & $279(85.0)$ \\
\hline Missing & $51(11.1)$ & $18(5.8)$ & $13(4.1)$ \\
\hline \multicolumn{4}{|c|}{ Have you changed how your volunteers engage? } \\
\hline Yes & $280(61.1)$ & $268(85.3)$ & $258(78.6)$ \\
\hline No & $119(26.0)$ & $34(10.8)$ & $64(19.8)$ \\
\hline Missing & 59 (12.9) & $12(3.9)$ & $6(1.6)$ \\
\hline \multicolumn{4}{|c|}{ How would you say you are deploying volunteers compared to before COVID-19? } \\
\hline A lot more & $12(2.6)$ & $11(3.3)$ & $12(3.6)$ \\
\hline Slightly more & $10(2.2)$ & $9(2.9)$ & $10(3.0)$ \\
\hline Slightly less & $29(6.3)$ & $29(9.3)$ & $29(8.8)$ \\
\hline Much less & $227(49.6)$ & $211(67.2)$ & $227(69.2)$ \\
\hline Missing & $130(28.4)$ & 31 (9.9) & $0(0)$ \\
\hline
\end{tabular}

Abbreviation: COVID-19, coronavirus disease 2019.

that of adaptation, where a minority of services adapted and changed the way they deployed volunteers.

\section{Protect and Prohibit}

Our quantitative data demonstrates a large decrease in the use of volunteers. Our free text data illuminates this, identifying that typically volunteers were either prohibited from supporting the service in the way that they usually did, or else because they were protected because they were perceived as particularly vulnerable to the effects of COVID-19. This was both because of local service based policies, or in response to national guidelines about the protection of those who were particularly vulnerable:

"Volunteers were temporarily told to stay home across the hospital. Elderly volunteers were told to stay longer periods at home for their protection" - Site 478 (Rest of world, Adult, Hospital).

"All volunteer work cancelled due to demographic of majority of volunteers, and concern about exposing them to COVID by charity" - Site 99 (UK, Adult, In Patient Unit [IPU]/Hospital advisory).

"No volunteers are called upon to offer their services. This is largely because our volunteers are generally over $65 y \mathrm{r}$ and there is fear from their families of undue exposure and risk."

- Site 25 (Rest of world, Adult, IPU).

Concerns about protecting volunteers from COVID-19 were noted both because of their personal vulnerabilities, the concerns of their families, and of affecting the institution's reputation if a volunteer contracted COVID-19 as a result of their involvement in the organisation. Institutional policies were often changed to directly prohibit volunteers from enacting their roles:

"Early corporate steer - no volunteers in the hospital" Site 188 (UK, Adult, Hospital).

"The hospital/trust have altered their policy on this. No ward volunteers, volunteers redeployed to eg, distributing donations" - Site 250 (UK, Adult, Hospital).

As well as protecting or prohibiting the volunteers themselves, preserving and prioritising both the distribution of PPE when there were shortages, and also the integrity of the site, was also important, with sites favouring so called 'essential' staff as opposed to volunteers. Despite most services reporting that they used volunteers in some capacity pre-pandemic, concerns about supporting and supervising 
Table 3. Characteristics of Services Indicating More or Less Volunteer Use During the COVID-19 Pandemic, With an Indication of Which Associations Between Characteristics Are Statistically Significant

\begin{tabular}{|c|c|c|c|c|c|c|c|}
\hline $\begin{array}{l}\text { Characteristic } \\
\text { (Present Yes/No) }\end{array}$ & & $\begin{array}{l}\text { Less Volunteer Use } \\
\qquad \begin{array}{c}(n=256) \\
\text { No. }(\%)\end{array}\end{array}$ & $\begin{array}{c}\text { Same/More Volunteer } \\
\text { Use }(n=72) \\
\text { No. }(\%)\end{array}$ & $\begin{array}{l}\text { All Services } \\
\text { (n= 328) } \\
\text { No. (\%) }\end{array}$ & $\begin{array}{l}\text { Missing } \\
\text { No. (\%) }\end{array}$ & $\chi^{2} / U$ & $P$ \\
\hline \multirow{2}{*}{ UK } & Yes & $160(62.5)$ & $35(48.6)$ & $195(59.5)$ & \multirow{2}{*}{$0(0)$} & \multirow{2}{*}{$\chi^{2}=4.5$} & \multirow{2}{*}{$.03 *$} \\
\hline & No & 96 (37.5) & 47 (51.4) & $133(40.5)$ & & & \\
\hline \multirow{2}{*}{ Rest of Europe } & Yes & $48(18.8)$ & $14(19.4)$ & $62(18.9)$ & \multirow{2}{*}{$0(0)$} & \multirow{2}{*}{$\chi^{2}=0.2$} & \multirow{2}{*}{.89} \\
\hline & No & $208(81.3)$ & $58(80.6)$ & $266(81.1)$ & & & \\
\hline \multirow{2}{*}{ Rest of world } & Yes & $48(18.8)$ & 23 (31.9) & 71 (21.6) & \multirow{2}{*}{$0(0)$} & \multirow{2}{*}{$\chi^{2}=5.8$} & \multirow{2}{*}{$.02 *$} \\
\hline & No & $208(81.3)$ & 49 (68.1) & $257(78.4)$ & & & \\
\hline \multirow{2}{*}{ Inpatient hospice } & Yes & $195(76.2)$ & $24(33.3)$ & $219(66.8)$ & \multirow{2}{*}{$0(0)$} & \multirow{2}{*}{$\chi^{2}=46.5$} & \multirow{2}{*}{$<.01^{*}$} \\
\hline & No & $61(23.8)$ & $48(66.7)$ & 109 (33.2) & & & \\
\hline \multirow{2}{*}{ Hospital palliative care team } & Yes & $102(39.8)$ & $37(51.4)$ & 139 (42.4) & \multirow{2}{*}{$0(0)$} & \multirow{2}{*}{$\chi^{2}=3.1$} & \multirow{2}{*}{.08} \\
\hline & No & $154(50.2)$ & 35 (48.6) & 189 (57.6) & & & \\
\hline \multirow{2}{*}{ Home palliative care } & Yes & $151(59.0)$ & $38(52.8)$ & 189 (57.6) & \multirow{2}{*}{$0(0)$} & \multirow{2}{*}{$\chi^{2}=0.9$} & \\
\hline & No & $105(41.0)$ & $34(47.2)$ & 139 (42.4) & & & .35 \\
\hline Home nursing & Yes & $85(33.2)$ & $15(20.8)$ & $100(30.5)$ & $0(0)$ & $x^{2}=41$ & $04 *$ \\
\hline nome nursing & No & $171(66.8)$ & $57(79.2)$ & $228(69.5)$ & & $x-4.1$ & \\
\hline Charitahle/non-nrofit funding & Yes & $155(60.5)$ & $21(29.2)$ & $176(53.7)$ & $3(09 \%)$ & $v^{2}-221$ & $<01 *$ \\
\hline 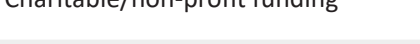 & No & $99(39.7)$ & $50(69.4)$ & $149(45.4)$ & $3(0.5 \%)$ & $X-2 L .1$ & -.01 \\
\hline Publir funding & Yes & $73(28.5)$ & $44(61.1)$ & $117(35.7)$ & $3(0,9)$ & $v^{2}-266$ & $<01 *$ \\
\hline 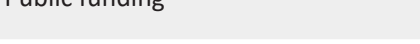 & No & $181(71.7)$ & $27(27.5)$ & $208(63.4)$ & $3(0.9 \%)$ & $x=\angle 6.6$ & $<.01$ \\
\hline Private/other funding & Yes & $26(10.2)$ & $6(8.3)$ & $32(9.8)$ & $3(09 \%)$ & $v^{2}=0 ?$ & 66 \\
\hline Private/vinet iumung & No & $228(89.1)$ & $65(90.3)$ & $293(89.3)$ & $3(0.9 \%)$ & $x-0.2$ & .00 \\
\hline & Adult only & $194(75.8)$ & $64(88.9)$ & $258(78.7)$ & & & \\
\hline Adult only, child only, or all patients & Child only & $21(8.2)$ & $2(2.8)$ & $23(7.0)$ & $5(1.5 \%)$ & $\chi^{2}=6.1$ & .11 \\
\hline & All patients & $37(14.5)$ & $5(6.9)$ & $42(12.8)$ & & & \\
\hline PPE shortages & Yes & $147(57.4)$ & $29(40.3)$ & $176(53.7)$ & $1(03 \%)$ & $\gamma^{2}=68$ & $01 *$ \\
\hline Staff shortages & Yes & $104(40.6)$ & $26(36.1)$ & $130(39.6)$ & $4(12 \%)$ & $v^{2}=06$ & 43 \\
\hline 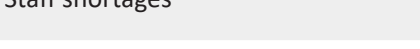 & No & $148(57.8)$ & $46(63.9)$ & $194(59.2)$ & $4(1.2 \%)$ & $x-0.0$ & .45 \\
\hline Innationt heds changes & Yes & $128(50.0)$ & $26(36.1)$ & $154(47.0)$ & $0(0)$ & $v^{2}-44$ & $04 *$ \\
\hline maptienit Neus Cinanges & No & $128(50.0)$ & $46(63.9)$ & $174(53.0)$ & 0 (U) & $x=-4.4$ & .04 \\
\hline Acute hospital patient support & Yes & $94(36.7)$ & $33(45.8)$ & $127(38.7)$ & $0(0)$ & $x^{2}=20$ & 16 \\
\hline changes & No & $162(63.3)$ & $39(54.2)$ & 201 (91.3) & $0(0)$ & $X^{2}=2.0$ & \\
\hline Specialist palliative care service & Yes & $154(60.2)$ & $36(50.0)$ & $190(57.9)$ & $0(0)$ & $\gamma^{2}=24$ & 12 \\
\hline changes & No & $102(39.8)$ & $36(50.0)$ & $138(42.1)$ & U(U) & $\chi^{2}=2.4$ & \\
\hline Hands-on home nursing care & Yes & $101(39.5)$ & $26(36.1)$ & $127(38.7)$ & $0(0)$ & $\gamma^{2}=03$ & 61 \\
\hline changes & No & $155(60.5)$ & $46(63.9)$ & $201(61.3)$ & $\mathrm{U}(0)$ & $X^{2}=0.3$ & .61 \\
\hline Cases of COVID-19 in staff & Yes & $198(77.3)$ & $53(73.6)$ & $251(76.5)$ & & & \\
\hline Cases of COVID-19 in statt & No & $56(21.9)$ & $19(26.4)$ & 75 (22.9) & $2(0.6 \%)$ & $\chi^{2}=0.6$ & .44 \\
\hline Caces of COVID-10 in volunteorc & Yes & $30(11.7)$ & $6(8.3)$ & $36(11.0)$ & $12(40 \%)$ & $v^{2}-07$ & 12 \\
\hline Cases of COVID-19 in volunteers & No & $216(84.4)$ & $63(87.5)$ & $279(85.1)$ & $13(4.0 \%)$ & $\chi^{2}=0.1$ & .42 \\
\hline Totalcacec of $c 0$ VI 10 in pationtc & $\mathrm{n}$ & $241(94.1)$ & $67(93.1)$ & 308 (92.9) & 6 & & 10 \\
\hline Total cases of COVID-19 in patients & Median (IQR) & $8(28)$ & $15(57)$ & $8(30)$ & $20(6.1 \%)$ & $U=7235.5$ & .19 \\
\hline & $n$ & $256(100.0)$ & $72(100.0)$ & $329(100.0)$ & $0(0)$ & $U=87740$ & 52 \\
\hline statt busyn & Median (IQR) & $3(3)$ & $2(3)$ & $3(3)$ & $0(0)$ & $U=8 / / 4.0$ & .52 \\
\hline
\end{tabular}

Abbreviations: COVID-19, coronavirus disease 2019; PPE, personal protective equipment; IQR, interquartile range.

* indicates a significant association.

volunteers during the pandemic also contributed to reductions in their deployment, with many of them not considering volunteers to be essential staff:

"Reduced ward-based volunteers to preserve PPE and reduce the footfall on the ward" - Site 59 (UK, IPU/ Hospice).
"Due to changes in services and changed working practices unable to support and supervise volunteers. Only essential staff working in the hospice hence no volunteers attending when families are in" - Site $\mathbf{5 2}$ (UK, Children, IPU).

Such decisions had a knock-on effect on staffing across the organisation, with staff being re-deployed to support 
Table 4. Service Characteristics Independently Associated With Less Volunteer Use During the COVID-19 Pandemic

\begin{tabular}{|c|c|c|c|c|}
\hline & \multirow{2}{*}{ OR } & \multicolumn{2}{|c|}{ OR $95 \% \mathrm{Cl}$} & \multirow{2}{*}{$P$} \\
\hline & & Lower & Upper & \\
\hline UK (no) & Ref & & & \\
\hline UK (yes) & 0.92 & 0.40 & 2.11 & .85 \\
\hline Rest of the world (no) & Ref & & & \\
\hline Rest of the world (yes) & 1.68 & 0.67 & 4.21 & .27 \\
\hline Inpatient hospice care (no) & Ref & & & \\
\hline Inpatient hospice care (yes) & 0.16 & 0.07 & 0.33 & $<.01$ \\
\hline Hands-on nursing care (no) & Ref & & & \\
\hline Hands-on nursing care (yes) & 0.99 & 0.46 & 2.14 & .98 \\
\hline $\begin{array}{l}\text { Charitable/non-profit management } \\
\text { (no) }\end{array}$ & Ref & & & \\
\hline $\begin{array}{l}\text { Charitable/non-profit management } \\
\text { (yes) }\end{array}$ & 1.18 & 0.35 & 3.95 & .79 \\
\hline Public management (no) & Ref & & & \\
\hline Public management (yes) & 2.51 & 0.85 & 7.42 & .10 \\
\hline PPE shortages (no) & Ref & & & \\
\hline PPE shortages (yes) & 1.03 & 0.52 & 2.04 & .94 \\
\hline Inpatient bed changes (no) & Ref & & & \\
\hline Inpatient bed changes (yes) & 1.72 & 0.83 & 3.56 & .15 \\
\hline
\end{tabular}

Abbreviations: COVID-19, coronavirus disease 2019; PPE, personal protective equipment; OR, odds ratio.

functions previously run by volunteers:

"Staff have been deployed so duties such as reception are being supported by staff" Site 47 (England, Adult, IPU/ Hospital/Home).

\section{Adaptation}

Some services had identified safe ways of adapting roles, or developed new functions that volunteers could more safely fulfil during the pandemic. This included support, befriending and bereavement roles, often delivered remotely. Other roles included services such as driving, delivering, shopping and gardening. Occasionally completely new roles were identified which could include those directly arising as a result of the pandemic (eg, making scrubs), but also coordination and information sharing roles. An example is the pivot to telephone or virtual support for patients already known to the organisation, and using skills that volunteers had already developed in existing in-person roles:

"We've asked all existing befriending or bereavement type volunteers to offer telephone support and soon to offer Facebook group bereavement support. We've asked Compassionate Neighbours to offer support to care home residents. We hope to set up a bereavement telephone helpline for any resident in [name of region] (and once lockdown eases we will need more volunteers to help act as a listening ear)" - Site 56 (UK Adult, IPU/Hospital/community).

"Now utilizing 'buddy program' where volunteers can call individuals and do a check in and offer support to help with social isolation and bridge the gap from quarantine at home and the community" - Site 373 (US/Adult/Hospital/ community).

More rarely, services imagined a completely new role for volunteers that hadn't been fulfilled in-person previously.
Examples included both new remote roles, such as facilitating the completion of care plans, or in-person roles such as providing hands-on nursing care:

"New volunteers helping patients with myCMC [coordinate my care - a care planning initiative]. Volunteers calling GP practices to get them to complete CMC plans. Volunteers calling care homes to navigate them through the creation of myCMC plans for their residents" - Site 76 (UK, Adult, IP/ Hospice).

"Additional volunteer training provided early on so that volunteers can provide basic patient care. This has been a really popular move for both volunteers and staff and will continue and develop" - Site 187 (UK, Adult, IPU).

\section{Discussion}

Palliative and hospice care services that had previously been reliant on a large volunteer body to support care often experienced a large decline in the presence of volunteers during the early phase of the COVID-19 pandemic, primarily due to their active withdrawal or suspension by the organisation to protect volunteers and focus on a core staff team. This is likely to have affected service capacity and delivery. Some palliative and hospice care organisations instituted new roles for volunteers, or moved existing roles to a remote way of working, but these appeared uncommon. In-patient hospices appeared particularly vulnerable to seeing reductions in volunteer use.

The management of risk within an organisation is important, but challenging to undertake at speed in a pandemic situation when new and previously unknown risks are presenting themselves. COVID-19 has highlighted the vulnerabilities of organisations, and led to challenging dilemmas about how to manage care standards in a crisis. ${ }^{33}$ It is perhaps understandable in this context that a simple solution to manage the risks associated with volunteers is to rapidly curtail their activities, particularly in small organisations that are high users of volunteers, such as many in-patient hospices. Writing plans and procedures to manage volunteers during a pandemic is possibly not an organisational priority. This has also happened previously, such as the suspension of volunteers during Avian flu. ${ }^{34}$ However, it must be recognised that in such a volunteer-rich specialty that this also carries risk, and ultimately may not be cost effective, and likely results in major reductions in elements of service capacity. There is evidence that responding to COVID-19 has strained the palliative care workforce, ${ }^{35}$ and surges in demand for endof-life care have exposed and exacerbated underlying gaps in access to specialty-trained physicians and teams, palliative care medications, and bereavement support for patients and families. ${ }^{36}$ At a time like this, not having a plan to use what can be a particularly common, valuable, knowledgeable, and committed resource such as volunteers, potentially adds to, rather than avoids, the risks and costs an organisation faces. A few services, however, did not curtail volunteer activities, but were able to respond more flexibly, and innovate rapidly. Our quantitative data did not identify any specific characteristics that determined what type of organisation was able to respond more flexibly. It is hard to unpick why these few services 
were outliers in innovative volunteer deployment, given the generally flexible, responsive and innovative nature of their general response to the pandemic reported elsewhere. ${ }^{3}$

It is likely that a major factor in the rapid cessation or curtailment of the use of volunteers was the perception, or reality, of many volunteers being particularly vulnerable to the effects of COVID-19 because of their age. Concerns were likely to be highlighted because of the large degree of uncertainty surrounding this new disease. ${ }^{37}$ We know that volunteers are predominantly older people. ${ }^{6}$ However, it could be argued that this view is potentially discriminatory, or ageist, and that the capacity of older people must be better used. Whilst assumptions may have been made about the technological capability of older people to switch to a remote form of operation, there is evidence that so called 'silver surfers' or 'digital immigrants' do use technology and can adapt rapidly to using it in ways that are appropriate to their age group. ${ }^{38,39}$ It is likely that older volunteers could have been better engaged by many organisations in areas such as the delivery of telephone or other forms of remote support, or shifted to other remote roles such as fundraising from home. It is critically important that we now work to shape future policies (and training) to optimally engage the resources of our aging population, and not unintentionally discriminate against those who are older as policies and procedures change. ${ }^{40}$

There is evidence that volunteers do not always feel informed about the organisation of patient care, or feel the organisation consistently takes their opinion into account. ${ }^{41}$ It is likely that volunteers themselves may have had the ability and capacity to produce the needed plans to enable new ways of working, if engaged and asked, although this may be difficult to do at speed and with competing priorities. Certainly, we know that some have argued for new roles for volunteers during the pandemic such as virtual volunteering. ${ }^{26,27,42}$ Some areas where volunteering is deeply embedded, such as in Kerala, have managed to emphasise community participation as part of their response to COVID, which includes supporting palliative care patients. ${ }^{43}$ This is not just seen in low-middle income countries, for example the calls for new volunteers in the United Kingdom such as the National Health Service (NHS) volunteering scheme were responded to by 750000 people. Here there is a paradox, volunteers are both seen as central to the response of a community or organisation, but equally not fully integrated into the response of the organisations for which they volunteer, not kept informed and on-board with the organisation, or not seen as 'essential,' and rapidly sidelined due to restrictive policies. For volunteers themselves, it is likely rarely about the tasks themselves, but about volunteering being a fundamental response; a desire to help. Their compassionate response to palliative care needs during COVID-19 should not be put to one side, but ways found of ensuring that they can again become a central and fundamental part of palliative and hospice care provision.

\section{Strengths and Limitations}

This was a large, multi-national survey with closed and freetext design giving insight and understanding. The open call, without any form of sampling, may have resulted in a particular type of organisation, or from particular countries, respond in patterns that are not known. There is not an equal distribution of responses across countries or clusters of countries. The way that this survey was constructed, with single responses covering multiple modes of service provision meant that it was not always possible to fully understand the impact of volunteer changes on specific types of services. The survey was also completed by service leads, and hence reflects their views, not those of volunteer coordinators nor the volunteers themselves. There were many services that did not provide information on change in volunteer deployment, and they may represent a different type of service. The survey was open for completion over a period of months, and it therefore also represents different times, in different countries, of the experience of the first wave of COVID-19. The temporal sequence of events is not known (eg, whether an increase in COVID-19 cases triggered a reduction in volunteer use). Free text comments, whilst commonly given, were often short with little context, so it was not always possible to fully interpret justifications for decisions made.

\section{Conclusion}

Volunteers, previously central to the support of many forms of palliative care, were mostly absent from organisations immediate response to COVID-19, particularly in-patient hospices. At a time where staffing has been affected by deployment changes and illness, this lack of a previously stable support may have affected both the scope, quality and safety of care. Flexible deployment plans need to be developed that protect volunteers, whilst still enabling them to have a role supporting care. Consideration needs to be given to widening the volunteer base away from those who may be considered to be most vulnerable to COVID-19, potentially engaging with younger people as volunteers. Further research needs to explore in more depth and detail what were the organisational factors that enabled some organisations to respond more flexibly, understand change over time during (and hopefully beyond) the COVID-19 pandemic, and with greater contextual information such as within countries or types of health and social care provision.

\section{Acknowledgements}

This study was part of CovPall, a multi-national study, supported by the Medical Research Council, National Institute for Health Research (NIHR) Applied Research Collaboration (ARC) South London (SL) and Cicely Saunders International. We thank all collaborators and advisors. We thank all participants, partners, PPI members and our Study Steering Group. We gratefully acknowledge technical assistance from the Precision Health Informatics Data Lab group (https:// phidatalab.org) at NIHR Biomedical Research Centre at SL and Maudsley NHS Foundation Trust and King's College London for the use of REDCap for data capture.

The CovPall Study Team consists of the following members: Professor Irene J Higginson (Chief Investigator), Dr Sabrina Bajwah (Co-I), Dr. Matthew Maddocks (Co-I), Professor Fliss Murtagh (Co-I), Professor Nancy Preston (Co-I), Dr. 
Katherine E Sleeman (Co-I), Professor Catherine Walshe (Co-I), Professor Lorna K Fraser (Co-I), Dr. Mevhibe B Hocaoglu (Co-I), Dr. Adejoke Oluyase (Co-I), Dr. Andrew Bradshaw, Lesley Dunleavy, Ian Garner and Rachel L Cripps. Additionally, the following memebers are the CovPall Study Partners: Hospice UK, Marie Curie, Sue Ryder, Palliative Outcome Scale Team, European Association of Palliative Care (EAPC), Together for Short Lives and Scottish Partnership for Palliative Care.

\section{Ethical issues}

Research ethics committee approval for this study was obtained from King's College London Research Ethics Committee (21/04/2020, Reference; LRS19/20-18541). ISRCTN16561225. Completion of survey indicated the participant had consented to the study.

\section{Competing interests}

Authors declare that they have no competing interests.

\section{Authors' contributions}

$\mathrm{IJH}$ is the grant holder and chief investigator; KES, MM, FEM, CW, NP, LKF, $\mathrm{SB}, \mathrm{MBH}$, and $\mathrm{AO}$ are co-applicants for funding. IJH and $\mathrm{CW}$ with critical input from all authors wrote the protocol for the CovPall study. $\mathrm{MBH}, \mathrm{AO}, \mathrm{RC}$, and LD co-ordinated data collection and liaised with centres, with input from $I J H$, FEM, CW, NP, and LKF. IG, MH, AO, LF, and CW analysed the data. All authors had access to all study data, discussed the interpretation of findings and take responsibility for data integrity and analysis. CW and IF drafted the manuscript. All authors contributed to the analysis plan and provided critical revision of the manuscript for important intellectual content.

\section{Funding}

This work was supported by UKRI and the NIHR [COV0011; MR/ V012908/1]. Additional support was from the NIHR, ARC, SL, hosted at King's College Hospital NHS Foundation Trust, and Cicely Saunders International (Registered Charity No. 1087195).

IJH is a NIHR Emeritus Senior Investigator and is supported by the NIHR ARC SL at King's College Hospital National Health Service Foundation Trust. IJH leads the Palliative and End of Life Care theme of the NIHR ARC SL and coleads the national theme in this. CW is supported by the NIHR Applied Research Collaboration North West Coast (ARC NWC, NIHR200182). MM is funded by a NIHR Career Development Fellowship (CDF-2017-10-009) and NIHR ARC SL. LKF is funded by a NIHR Career Development Fellowship (award CDF2018-11-ST2-002). KES is funded by a NIHR Clinician Scientist Fellowship (CS-2015-15-005). RC is funded by Cicely Saunders International. FEM is a NIHR Senior Investigator. MBH is supported by the NIHR ARC SL. The views expressed in this article are those of the authors and not necessarily those of the NIHR, or the Department of Health and Social Care.

\section{Data sharing}

Applications for use of the survey data can be made for up to 10 years, and will be considered on a case by case basis on receipt of a methodological sound proposal to achieve aims in line with the original protocol. The study protocol is available on request. All requests for data access should be addressed to the Chief Investigator via the details on the CovPall website (https://www.kcl. ac.uk/cicelysaunders/research/evaluating/covpall-study, and palliativecare@kcl. ac.uk) and will be reviewed by the Study Steering Group.

\section{Authors' affiliations}

${ }^{1}$ International Observatory on End of Life Care, Lancaster University, Lancaster, UK. ${ }^{2}$ Wolfson Palliative Care Research Centre, Hull York Medical School, University of Hull, Hull, UK. ${ }^{3}$ Cicely Saunders Institute of Palliative Care, Policy \& Rehabilitation, King's College, London, UK. ${ }^{4}$ The Martin House Research Centre, Department of Health Sciences, University of York, York, UK.

\section{Supplementary files}

Supplementary file 1. CovPall Collaboration Survey.

\section{References}

1. Bradshaw A, Dunleavy L, Walshe C, et al. Understanding and addressing challenges for advance care planning in the COVID-19 pandemic: an analysis of the UK CovPall survey data from specialist palliative care services. Palliat Med. 2021;35(7):1225-1237. doi:10.1177/02692163211017387

2. Oluyase $A O$, Hocaoglu $M$, Cripps $R L$, et al. The challenges of caring for people dying from COVID-19: a multinational, observational study (CovPall). J Pain Symptom Manage. 2021;62(3):460-470. doi:10.1016/j. jpainsymman.2021.01.138

3. Dunleavy L, Preston N, Bajwah S, et al. 'Necessity is the mother of invention': specialist palliative care service innovation and practice change in response to COVID-19. Results from a multinational survey (CovPall). Palliat Med. 2021;35(5):814-829. doi:10.1177/02692163211000660

4. Scott R, Goossensen A, Payne S, Pelttari L. What it means to be a palliative care volunteer in eight European countries: a qualitative analysis of accounts of volunteering. Scand J Caring Sci. 2021;35(1):170-177. doi:10.1111/scs.12832

5. Burbeck R, Low J, Sampson EL, et al. Volunteers in specialist palliative care: a survey of adult services in the United Kingdom. J Palliat Med. 2014;17(5):568-574. doi:10.1089/jpm.2013.0157

6. Vanderstichelen S, Cohen J, Van Wesemael Y, Deliens L, Chambaere K. Volunteers in palliative care: a healthcare system-wide crosssectional survey. BMJ Support Palliat Care. 2020. doi:10.1136/ bmjspcare-2020-002321

7. Gaskin K. The Economics of Hospice Volunteering. London: Hospice Information; 2003.

8. Bloomer MJ, Walshe C. 'It's not what they were expecting': a systematic review and narrative synthesis of the role and experience of the hospital palliative care volunteer. Palliat Med. 2020;34(5):589-604. doi:10.1177/0269216319899025

9. Walshe C, Dodd S, Hill M, et al. How effective are volunteers at supporting people in their last year of life? a pragmatic randomised wait-list trial in palliative care (ELSA). BMC Med. 2016;14(1):203. doi:10.1186/s12916016-0746-8

10. Burbeck R, Candy B, Low J, Rees R. Understanding the role of the volunteer in specialist palliative care: a systematic review and thematic synthesis of qualitative studies. BMC Palliat Care. 2014;13(1):3. doi:10.1186/1472-684x-13-3

11. Claxton-Oldfield S. Hospice palliative care volunteers: the benefits for patients, family caregivers, and the volunteers. Palliat Support Care. 2015;13(3):809-813. doi:10.1017/s1478951514000674

12. Naylor C, Mundle C, Weaks L, Buck D. Volunteering in Health and Care: Securing a Sustainable Future. London: The King's Fund; 2013.

13. Lorhan S, Wright M, Hodgson S, van der Westhuizen M. The development and implementation of a volunteer lay navigation competency framework at an outpatient cancer center. Support Care Cancer. 2014;22(9):25712580. doi:10.1007/s00520-014-2238-8

14. Morris S, Wilmot A, Hill M, Ockenden N, Payne S. A narrative literature review of the contribution of volunteers in end-of-life care services. Palliat Med. 2013;27(5):428-436. doi:10.1177/0269216312453608

15. Nissim R, Regehr M, Rozmovits L, Rodin G. Transforming the experience of cancer care: a qualitative study of a hospital-based volunteer psychosocial support service. Support Care Cancer. 2009;17(7):801-809. doi:10.1007/s00520-008-0556-4

16. Dunleavy L, Walshe C, Machin L. Exploring the psychological impact of life-limiting illness using the attitude to health change scales: a qualitative focus group study in a hospice palliative care setting. Eur J Cancer Care (Engl). 2020;29(6):e13302. doi:10.1111/ecc.13302

17. Vanderstichelen S, Cohen J, Van Wesemael Y, Deliens L, Chambaere $\mathrm{K}$. The liminal space palliative care volunteers occupy and their roles within it: a qualitative study. BMJ Support Palliat Care. 2020;10(3):e28. doi:10.1136/bmjspcare-2018-001632

18. Dodd S, Hill M, Ockenden N, et al. 'Being with' or 'doing for'? how the role of an end-of-life volunteer befriender can impact patient wellbeing: interviews from a multiple qualitative case study (ELSA). Support Care Cancer. 2018;26(9):3163-3172. doi:10.1007/s00520-018-4169-2

19. Luijkx KG, Schols JM. Volunteers in palliative care make a difference. $J$ Palliat Care. 2009;25(1):30-39.

20. Gardiner C, Barnes S. The impact of volunteer befriending services for older people at the end of life: mechanisms supporting wellbeing. Prog Palliat Care. 2016;24(3):159-164. doi:10.1080/09699260.2015.1116728

21. Candy B, France R, Low J, Sampson L. Does involving volunteers in the provision of palliative care make a difference to patient and family wellbeing? a systematic review of quantitative and qualitative evidence. 
Int J Nurs Stud. 2015;52(3):756-768. doi:10.1016/j.ijnurstu.2014.08.007

22. Herbst-Damm KL, Kulik JA. Volunteer support, marital status, and the survival times of terminally ill patients. Health Psychol. 2005;24(2):225229. doi:10.1037/0278-6133.24.2.225

23. Söderhamn $U$, Flateland $S$, Fensli $M$, Skaar R. To be a trained and supported volunteer in palliative care - a phenomenological study. BMC Palliat Care. 2017;16(1):18. doi:10.1186/s12904-017-0193-0

24. Beasley E, Brooker J, Warren N, et al. The lived experience of volunteering in a palliative care biography service. Palliat Support Care. 2015;13(5):1417-1425. doi:10.1017/s1478951515000152

25. Coleman $\mathrm{H}$, Walshe $\mathrm{C}$. What are the emotional experiences of being a volunteer in palliative and end-of-life care settings? a systematic review and thematic synthesis. J Pain Symptom Manage. 2021;62(3):e232-e247. doi:10.1016/j.jpainsymman.2021.02.025

26. Knights D, Knights F, Lawrie I. Upside down solutions: palliative care and COVID-19. BMJ Support Palliat Care. 2020. doi:10.1136/ bmjspcare-2020-002385

27. Radbruch L, Knaul FM, de Lima L, de Joncheere C, Bhadelia A. The key role of palliative care in response to the COVID-19 tsunami of suffering. Lancet. 2020;395(10235):1467-1469. doi:10.1016/s01406736(20)30964-8

28. von Elm E, Altman DG, Egger M, Pocock SJ, Gøtzsche PC, Vandenbroucke JP. The Strengthening the Reporting of Observational Studies in Epidemiology (STROBE) statement: guidelines for reporting observational studies. J Clin Epidemiol. 2008;61(4):344-349. doi:10.1016/j.jclinepi.2007.11.008

29. Eysenbach G. Improving the quality of web surveys: the Checklist for Reporting Results of Internet E-Surveys (CHERRIES). J Med Internet Res. 2004;6(3):e34. doi:10.2196/jmir.6.3.e34

30. Garcia J, Evans J, Reshaw M. "Is there anything else you would like to tell us" - Methodological issues in the use of free-text comments from postal surveys. Qual Quant. 2004;38(2):113-125. doi:10.1023/ B:QUQU.0000019394.78970.df

31. O'Cathain A, Thomas KJ. "Any other comments?" open questions on questionnaires - a bane or a bonus to research? BMC Med Res Methodol. 2004;4:25. doi:10.1186/1471-2288-4-25

32. Hsieh H-F, Shannon SE. Three approaches to qualitative content analysis. Qual Health Res. 2005;15(9):1277-1288. doi:10.1177/1049732305276687
33. Chuang E, Cuartas PA, Powell T, Gong MN. "We're not ready, but i don't think you're ever ready." Clinician perspectives on implementation of crisis standards of care. AJOB Empir Bioeth. 2020;11(3):148-159. doi:10.1080/ 23294515.2020.1759731

34. Cheng HW, Li CW, Chan KY, Sham MK. The first confirmed case of human avian influenza $\mathrm{A}(\mathrm{H} 7 \mathrm{~N} 9)$ in Hong Kong and the suspension of volunteer services: impact on palliative care. J Pain Symptom Manage. 2014;47(6):e5-7. doi:10.1016/j.jpainsymman.2013.12.234

35. Kates J, Gerolamo A, Pogorzelska-Maziarz M. The impact of COVID-19 on the hospice and palliative care workforce. Public Health Nurs. 2021; 38(3):459-463. doi:10.1111/phn.12827

36. Abbott J, Johnson D, Wynia M. Ensuring adequate palliative and hospice care during COVID-19 surges. JAMA. 2020;324(14):1393-1394. doi:10.1001/jama.2020.16843

37. Koffman J, Gross J, Etkind SN, Selman L. Uncertainty and COVID-19: how are we to respond? J $R$ Soc Med. 2020;113(6):211-216. doi:10.1177/0141076820930665

38. Fietkiewicz K. Jumping the digital divide: how do "silver surfers" and "digital immigrants" use social media? Networking Knowledge: Journal of the MeCCSA Postgraduate Network. 2017;10(1):5-26. doi:10.31165/ nk.2017.101.494

39. Vulpe S, Crăciun A. Silver surfers from a European perspective: technology communication usage among European seniors. Eur J Ageing. 2020;17(1):125-134. doi:10.1007/s10433-019-00520-2

40. Gonzales E, Matz-Costa C, Morrow-Howell N. Increasing opportunities for the productive engagement of older adults: a response to population aging. Gerontologist. 2015;55(2):252-261. doi:10.1093/geront/gnu176

41. Vanderstichelen S, Cohen J, Van Wesemael Y, Deliens L, Chambaere K. The involvement of volunteers in palliative care and their collaboration with healthcare professionals: a cross-sectional volunteer survey across the Flemish healthcare system (Belgium). Health Soc Care Community. 2020;28(3):747-761. doi:10.1111/hsc.12905

42. Pickell Z, Gu K, Williams AM. Virtual volunteers: the importance of restructuring medical volunteering during the COVID-19 pandemic. Med Humanit. 2020;46(4):537-540. doi:10.1136/medhum-2020-011956

43. Menon JC, Rakesh PS, John D, Thachathodiyl R, Banerjee A. What was right about Kerala's response to the COVID-19 pandemic? BMJ Glob Health. 2020;5(7):e003212. doi:10.1136/bmjgh-2020-003212 